\title{
Ritual Mungkah Wali Sebagai Kearifan Ekologi Bagi Masyrakat Desa Tambakan, Kecamatan Kubutambahan, Kabupaten Buleleng
}

\author{
I Putu Yudi Santika ${ }^{1 *}$, Ni Luh Arjani ${ }^{2}$ \\ ${ }^{[123]}$ Prodi Antropologi Fakultas Ilmu Budaya Unud \\ ${ }^{1}$ [ipys4115@gmail.com], ${ }^{2}$ [arjani_psw@yahoo.com] \\ *Corresponding Author
}

\begin{abstract}
Tambakan people are able to maintain their ecological balance through local wisdom is reflected in the annual ritual behavior called Mungkah Wali. The purpose of this study is to know: (a) Why Tambakan people perform a ritual called Mungkah Wali , (b) How is the Mungkah Wali ritual process implemented and (c) What is the meaning of Mungkah Wali ritual for Tambakan society? This research uses ethnographic research method which is included in qualitative research with data collection technique through participant observation, interview, and literature study. This research using Functional Structural theory in reviewing structure and function of Mungkah Wali ritual to understand and analyze the research data, and uses Semiologi theory to study the myth contained in the ritual. Based on the analysis, this study found three factors behind the implementation of Mungkah Wali ritual that are (a) as the worship of God; (b) carrying out mythical rituals; (c) relate to the history of the establishment of Tambak Village. The function of the Mungkah Wali ritual is for offering to obtain the grace in the form of safety, welfare, and prosperity for Tambakan Village. The meaning of the Mungkah Wali ritual is: (a) having an unifying or solidarity function among the community; (b) having a preservation function for forest area in Tambakan Village; (c) has a function in maintaining water availability in Desa Tambakan; (d) has a function of preserving the cow population; (e) has an economic function for the community of Desa Tambakan
\end{abstract}

Key Words : Ecological Wisdom, Bulu Geles, Ritual Mungkah Wali

\begin{abstract}
Abstrak
Masyarakat Tambakan mampu mempertahankan keseimbangan ekologi mereka melalui kearifan lokal yang tercermin dari perilaku ritual tahunan yaitu Mungkah Wali. Adapun penelitian ini bertujuan untuk mengetahui: (a) mengapa masyarakat Tambakan melakasanakan ritual Mungkah Wali, (b) bagaimanakah proses ritual Mungkah Wali, serta (c) apakah makna ritual Mungkah Wali bagi masyarakat Tambakan. Penelitian ini menggunakan metode penelitian etnografi yang termasuk ke dalam penelitian kualitatif dengan teknik pengumpulan data melalui observasi partisipasi, wawancara, serta studi kepustakaan. Untuk memahami dan menganalisis data penelitian digunakan teori Struktural Fungsional dalam mengkaji struktur serta fungsi ritual Mungkah Wali, kemudian teori Semiologi mengkaji mitos yang terdapat dalam ritual. Berdasarkan analisis tersebut, penelitian ini menemukan tiga faktor yang melatarbelakangi pelaksanaan ritual Mungkah Wali yaitu (a) sebagai pemujaan terhadap Dewa; (b)
\end{abstract}


melaksanakan ritual yang berlatar mitos; (c) berhubungan dengan sejarah pembentukan Desa tambakan. Fungsi dari ritual Mungkah Wali adalah fungsi persembahan untuk memperoleh anugrah berupa keselamatan, kesejahteraan, serta kemakmuran bagi Desa Tambakan. Makna dari ritual Mungkah Wali yaitu: (a) memiliki fungsi pemersatu atau solidaritas antar masyarakat Tambakan; (b) memiliki fungsi pelestarian terhadap kawasan hutan di Desa Tambakan; (c) memiliki fungsi dalam menjaga ketersediaan air di Desa Tambakan; (d) memiliki fungsi pelestarian populasi sapi; (e) memiliki fungsi ekonomis bagi masyarakat Desa Tambakan.

Kata kunci : Kearifan Ekologi, Bulu Geles, Ritual Mungkah Wali

\section{Latar Belakang}

Pemerintah telah membuat UndangUndang untuk mencegah kerusakan lingkungan yang disebabkan oleh manusia seperti Rencana Tata Ruang Wilayah (RTRW) Provinsi Bali. RTRW Provinsi Bali dibentuk guna mengatur tata ruang wilayah di Bali agar sesuai dengan filosofi Tri Hita Karana serta berbasiskan kearifan lokal supaya dalam pembangunan-pembangunan di Bali tidak merusak lingkungan. Namun kerusakan yang terjadi pada lingkungan pada sejumlah kawasan di Bali membuat peraturan tersebut hanyalah formalitas hukum yang tidak secara tegas menangani penyimpangan yang dilakukan oleh oknum yang tidak bertanggung jawab.

Masyarakat Tambakan memiliki ritual Mungkah Wali yang dilaksanakan setiap Purnama Kasa, ritual ini memiliki dampak tidak langsung bagi lingkungan sekitar kawasan hutan Desa Tambakan. Ritual Mungkah Wali memiliki rangkaian prosesi yang berkaitan dengan kearifan ekologi Desa Tambakan. Prosesproses ekologi memiliki hukum timbal balik, antara budaya dan lingkungan, bukan entitas yang masing-masing berdiri sendiri atau bukan barang jadi yang bersifat statis, keduanya saling mempengaruhi, tetapi pada waktu yang sama manusia juga mempengaruhi perubahan-perubahan lingkungan (Susilo, 2012: 47). Sebagai kesatuan yang saling berhubungan, masyarakat Tambakan cukup sukses dalam menjaga ekologi mereka, disamping itu hutan menjadi sentral bagi kehidupan masyarakat Tambakan.

\section{Pokok Permasalahan}

a. Mengapa ritual Mungkah Wali di Desa Tambakan masih tetap dilaksanakan?

b. Bagaimanakah proses pelaksanaan ritual Mungkah Wali di Desa Tambakan?

c. Apakah makna ritual Mungkah Wali bagi masyarakat Desa Tambakan?

\section{Tujuan Penelitian}

a. Mengetahui alasan dibalik tetap dilaksanakannya ritual Mungkah Wali oleh masyarakat Tambakan.

b. Mengetahui proses dari ritual Mungkah Wali di Desa Tambakan.

c. Memahami makna yang terkandung dalam ritual Mungkah Wali tersebut.

\section{Metode Penelitian}

Penelitian ini dilakukan di Desa Tambakan, Kecamatan Kubutambahan, Kabupaten Buleleng Provinsi Bali yang berbatasan dengan Desa Catur Kecamatan Kintamani Bangli. Penelitian ini memfokuskan sasaran kepada masyarakat Bali Aga di Desa Tambakan. Pemilihan Desa Tambakan didasari atas adanya ritual Mungkah Wali yang memiliki dampak secara tidak langsung 
terhadap lingkungan masyarakat Tambakan, di mana terdapat kearifan ekologi dalam setiap tahapan ritual tersebut. Untuk penentuan Kriteria informan kunci yang dipilih sebagai berikut: a) berdasarkan keterlibatannya dalam praktek ritual Mungkah Wali, b) pengalaman dalam kegiatan ritual, serta c) merupakan seorang tokoh yang berperan penting dalam proses pelaksanaan ritual.

\section{Hasil dan Pembahasan}

\subsection{Latar Belakang Dilaksanakannya Ritual Mugkah Wali}

Masyarakat Tambakan melaksanakan ritual Mungkah Wali sebagai kehendak dari Dewa yang mereka puja. Segala aktifitas termasuk sarana ritual di Desa Tambakan merupakan bentuk konkret dari pemujaan terhadap Dewa di sana. Mereka melakukan ritual Mungkah Wali sebagai bentuk rasa hormat dan bakti terhadap leluhur dan juga Dewa di Desa Tambakan. Ritual Mungkah wali memiliki mitos yaitu Bulu Geles yang menjadi dasar keyakinan dalam ritual Nawur Bulu Geles dan Masegehan. Mitos ini diturunkan secara lisan oleh masyarakat Tambakan di mana menandakan kepercayaan terhadap sesuatu yang tersucikan dari hewan berupa sapi sebagai simbolisasi Dewa Siwa. Mitos Bulu Geles melatarbelakangi penggunaan sapi sebagai korban suci pada beberapa ritual di masyarakat Bali terutama di Desa Tambakan. Ritual Mungkah Wali tetap dilaksanakan oleh masyarakat Tambakan karena berkaitan dengan sejarah dari pembentukan desa tersebut. Setelah penduduk padangluah mengungsi di daerah Tambakan sekarang, mereka mengucapkan kaul agar keberadaan mereka tidak diketahui oleh musuh kala itu. Setelah keinginan mereka terpenuhi barulah segera kaul tersebut dibayar dengan mempersembahkan sapi atau Godel (nama anak dari sapi) kehadapan Dewa mereka. Sapi ini tidak dipotong melainkan dilepaskan begitu saja ke alam bebas namun, pelepasan tersebut melalui ritual penyucian sehingga sapi yang dipersembahkan tidak lagi memiliki status sebagai sapi biasa tetapi sapi suci oleh masyarakat Tambakan disebut Duwe Tambakan.

\subsection{Proses Mungkah Wali}

Tahapan pertama dari ritual ini adalah Nawur Bulu Geles yang dilaksanakan bertepatan pada hari Tilem. Persembahannya menggunakan sapi jantan yang selanjutnya disucikan di Pura Dalem Tambakan, setelah itu dilepas ke alam bebas oleh para tetua adat. Pada hari Purnama Kadasa diadakanlah prosesi Masegehang di mana sapi yang dilepaskan ditangkap kemudian disembelih di Pura Prajapati. Diantara sapi yang ditangkap dipilih satu saja untuk dipersembahkan di dalam Pura yang disusun membentuk plupuan. Daging sapi yang tersisa selanjutnya dibagikan kepada masyarakat Tambakan serta dijual kepada masyarakat luar. Tahapan-tahapan berikutnya dilanjutkan dengan piodalan-piodalan yang jatuh pada rahinan Purnama di Pura Desa maupun Pura Dalem Desa Tambakan

\subsection{Kearifan Ekologi Terkait ritual Mungkah Wali}

Ritual Mungkah Wali memiliki makna solidaritas terhadap seluruh lapisan masyarakat di Desa Tambakan. Masyarakat memiliki rasa saling memiliki, sehingga sifat gotong royong dan saling membantu akan muncul seiring dengan kewajiban untuk melaksanakan ritual Mungkah Wali namun, tetap bersifat sakral. Robertson Smith (dalam Koentjaraningrat, 1987: 67) mengutarakan gagasan mengenai upacara religi atau agama yang 
dilaksanakan masyarakat banyak mempunyai fungsi sosial untuk mengintensifkan solidaritas masyarakat. Menurut Smith motivasi dalam melaksanakan kegiatan ritual bukan terutama berbakti kepada Dewa atau Tuhan tetapi, mereka menganggap bahwa melakukan upacara adalah suatu kewajiban sosial.

Fungsi azasi dari religi atau agama sebagai pendorong solidaritas sosial juga dikemukakan oleh E. Durkheim (dalam koentjaraningrat, 1992: 234) di mana asal mula religi berasal dari sentimen kemasyarakatan yang berpusat kepada beberapa pengertian dasar. Munculnya aktiviet religi dikarenakan suatu getaran jiwa, suatu emosi keagamaan, yang timbul karena pengaruh rasa sentimen kemasyarakatan berupa suatu kompleks perasaan yang menandung rasa terikat, rasa bakti, rasa cinta dan sebagainya terhadap masyarakatnya sendiri. Tetapi sentimen kemasyarakatan dapat menjadi lemah, oleh karena itu dalam penguatannya kembali adalah dengan mengadakan suatu kontraksi masyarakat. Emosi keagamaan yang timbul karena sentimen kemasyarakatan membutuhkan obyek tujuan sehingga obyek terrsebut mempunyai sifat keramat (sacré). Obyek tersebut berupa sejenis binatang, tumbuhtumbuhan, maupun sebuah benda.

Ritual tersebut juga memiliki fungsi konservasi hutan karena keberadaan sapi suci menyebar luas di kawasan Tambakan. Adanya mitos bahwa sapi suci merupakan bagian dari Bhatara di Pura Dalem membuat masyarakat menjaga sikapnya bila mengadakan kontak dengan sapi suci ini. sapi tersebut menggantungkan hidupnya dari alam, mereka mendiami kawasan hutan dan menjadikannya tempat tinggal. Agar terpeliharanya sapi suci masyarakat Tambakan juga harus merawat alam sekitarnya tetapi, tidak ada perlakuan khusus dalam perawatannya, serta tidak juga terjadi eksploitasi yang berlebihan pada kawasan hutan di sana. Sapi suci ini juga dapat menjadi pupuk berjalan bagi tanaman di lingkungan Tambakan. Dengan terjaganya kawasan hutan tersebut ikut menjaga beberapa manfaat bagi kehidupan masyarakat Tambakan.

Ritual Mungkah Wali menjaga ketersediaan sumber air di Desa Tambakan. Fungsi air begitu peting dalam kehidupan sehari-hari masyarakat Tambakan sehingga mereka mengadakan ritual di sumber mata air serta mendirikan tempat pemujaan berdekatan dengan sumber mata air tersebut seperti di Pura Beji. Ritual Mungkah Wali juga menjadi representasi dari praktek ritual yang dilakukan untuk menghormati sumber mata air seperti ritual Melasti. Dengan tetap dilaksanakannya ritual ini maka, ketersedian air di Desa Tambakan dapat terjamin. Kebutuhan akan air pribadi masyarakat juga ikut terpenuhi. Disamping beberapa desa lain yang mungkin kekurangan air, Desa Tambakan mampu menjaga eklogi air di desa mereka.

Desa Tambakan mampu melestarikan sumber daya sapi di mana ketika diadakannya ritual Masegehan, sapi suci Tambakan disembelih, diambil darah, daging, serta organ lainnya. Pengorbanan sapi tersebut tidak hanya seekor saja, melainkan puluhan sapi. Tetapi populasi sapi suci itu akan tetap lestari keberadaannya karena adanya ritual Nawur Bulu Geles dan dapat dikorbankan kembali dalam ritual Masegehan. Menurut keterangan Jro Mangku Dalem, ketika ritual Nawur Bulu Geles dilakukan, sapi suci yang dilepas ke hutan dapat berjumlah dua sampai empat ekor dalam sebulan bertepatan dengan hari tilem. Bila diakumulasikan, rata-rata pertahun populasi sapi suci dapat mencapai 24 ekor setelah dua tahun akan 
menjadi 48 ekor. Dalam ritual Masegehan dikorbankan sebanyak 30 ekor dengan demikian masih tersisa 18 ekor di sekitaran desa. Sapi suci ini tidak hanya berdiam di kawasan Desa Tambakan tetapi di luar desa hingga ke Kabupaten lain di wilayah Bali.

Berdasarkan pemaparan di atas diperoleh gambaran bahwa, keseimbangan antara populasi sapi dengan kebutuhan ritual dapat berjalan selaras. Meski sapi suci tersebut dikorbankan dalam ritual Mungkah Wali populasi sapi tersebut tidaklah berkurang atau terancam punah, justru berkembang mendiami beberapa daerah di Bali Utara. Apabila binatang disucikan serta diciptakan perpaduan antara pemeliharaan melalui mitos serta perlakuan tertentu dalam ritual maka kepunahan dapat dihindari.

Ritual Mungkah Wali memiliki manfaat ekonomi dalam pelaksanaan tahapannya. Pembayar atas daging sapi ini disebut ampelan, dana ini dikelola oleh Jro Bendesa untuk keperluan yang berkaitan dengan kebutuhan desa. Sapi suci ini memiliki ukuran badan yang besar sehingga daging yang didapakan lumayan banyak bahkan dapat dilelang kepada pihak luar, daging sapi ini lebih banyak daripada harga dipasaran. Manfaat ekonomi bukan hanya dirasakan oleh masayarakat Tambakan melainkan juga masyarakat luar desa. Hasil dari pelelangan ini juga digunakan untuk kebutuhan ritual Mungkah Wali, meski persiapannya menggunakan bahan dan hasil dari lahan di Desa Tambakan, ada bahan ritual yang tidak ada di Desa Tambakan seperti janur atau kelapa.

\section{Simpulan}

Berdasarkan pembahasan dan analisis tentang ritual Mungkah Wali sebagai kearifan ekologi masyarakat Desa Tambakan, Kecamatan Kubutambahan,
Buleleng dapat ditarik kesimpulan yaitu, ritual Mungkah Wali tetap dilaksanakan secara konsisten dikarenakan oleh beberapa faktor diantaranya, berkaitan dengan pemujaan terhadap Dewa mereka di mana, kebutuhan ritual merupakan kehendak dari para Dewa. Selain hal tersebut, dalam ritual Mungkah Wali merupakan pelaksanaan ritual yang berlatar mitos, dinamakan mitos Bulu Geles. ritual Mungkah Wali dilaksanakan karena memiliki hubungan dengan sejarah dari pembentukan Desa Tambakan.

Ritual Mungkah Wali sama sistemnya dengan Ngusaba Desa yaitu memiliki tahapan-tahapan dalam perayaannya. Tahapan pertama dilaksanakan ritual Nawur Bulu Geles di mana anak sapi yang dipersembahkan disucikan dan dilepaskan ke alam bebas, dilaksanakan secara priodik pada hari Tilem. Tahapan kedua dilaksanakannya ritual Masegehan yang bertepatan pada purnama kasa setiap dua tahun sekali, dalam ritual ini sapi suci yang dilepas tersebut ditangkap dan disembelih di Pura Prajapati. Tahapan selanjutnya merupakan piodalan sebagai perayaan wali di Pura Desa, Pura Dalem, Pura Ibu, dan Pura Cemara. Perayaan setiap tahapan tersebut bertepatan pada purnama dan juga tilem. Tujuan diadakannya ritual Mungkah Wali adalah memohon keselamatan dari para Dewa agar terhindar dari segala kemalangan dan mendapatkan kemakmuran bagi masyarakat Desa.

Ritual Mungkah Wali memiliki fungsi laten yang berdampak langsung pada kehidupan masyarakat Tambakan. Fungsi tersebut meliputi fungsi ekologis terkait pelestarian kawasan hutan, pelestarian sumber daya air, pelestarian sapi serta memiliki makna solidaritas dan ekonomis. Sapi suci yang berkeliaran bebas di kawasan hutan merupakan 
habitat tempat tinggal mereka, maka dari itu masyarakat Tambakan harus menjaga hutan karena keberadaan mereka di dalam hutan tersebut. Kawasan hutan yang terjaga memiliki implikasi bagi ketersediaan air di Tambakan. Air memiliki peranan penting bagi ritual maupun untuk kebutuhan konsumsi para warga. Dengan terselenggaranya Mungkah Wali kelestarian sapi akan terjaga populasinya karena persembahan sapi dan mitos yang mengikatnya membuat keberadaan sapi tersebut tetap lestari. Pelepasan sapi suci membuat populasinya kian bertambah, tetapi setiap dua tahun sekali puluhan sapi suci ini akan disembelih sehingga ketersediaan populasi dan sumber daya akan seimbang.

Makna solidaritas juga tercermin dalam pelaksanaan ritual Mungkah Wali. Ritual menjadi alat pemersatu karena saat ritual menjadi arena anggota masyarakat berkumpul dan saling berinteraksi. Ritual tersebut juga memilliki makna ekonomis bagi masyarakat Tambakan maupun pihak luar desa. Sisa dari daging sapi Duwe tersebut dilelang oleh masyarakat, dari dana yang terkumpul akan dimasukan dalam khas desa serta dipergunakan untuk menyiapkan kebutuhan ritual. Daging sapi yang dilelang ketika perayaan ritual Masegehan lebih murah dan masyarakat mendapatkan bagian lumayan banyak, sehingga ritual ini memiliki fungsi ekonomis.

\section{Saran}

Saran yang dapat diberikan penulis adalah adanya perhatian terhadap pelestarian lingkungan berbasiskan kearifan lokal. Dalam beberapa dekade permasalahan lingkungan sering bermunculan seiring dengan perkembangan zaman. Meski norma modern telah dibentuk, serta lembaga khusus telah dibangun, masih saja belum efektif untuk menangani kerusakan lingkungan. Sebenarnya kelestarian lingkungan berbasis kearifan lokal sudah lama disosialisikan oleh pihak yang mengutarakan bahwa kearifan lokal merupakan pemecah masalah kerusakan lingkungan saat ini. Fenomena ritual Mungkah Wali merupakan suatu resonalitas tersembunyi dibalik setiap prilaku ritual masyarakat Tambakan yang memiliki manfaat bagi lingkungan Desa Tambakan itu sendiri. Semoga dengan tulisan ini mampu membuka kesadaran baru bagi kita semua untuk melestarikan lingkungan.

\section{Daftar Pustaka}

Susilo, Dwi K. 2012. Sosiologi Lingkungan. Jakarta : Pt Rajagrafindo Persada.

Koentjaraningrat. 2010. Sejarah Teori Antropologi. Jakarta: Universitas Indonesia 